\title{
The expression of ovine placental lactogen, StAR and progesterone-associated steroidogenic enzymes in placentae of overnourished growing adolescent ewes
}

\author{
Richard G Lea, Peter Wooding ${ }^{1}$, Ian Stewart ${ }^{2}$, Lisa T Hannah, Stephen Morton, Karen Wallace, \\ Raymond P Aitken, John S Milne, Timothy R Regnault ${ }^{3}$, Russell V Anthony ${ }^{3,4}$ and Jacqueline \\ $M$ Wallace
}

Rowett Research Institute, Bucksburn, Aberdeen AB21 9SB, UK, ${ }^{1}$ Department of Physiology, University of Cambridge, Cambridge, UK, ${ }^{2}$ School of Medical Sciences, University of Aberdeen, Aberdeen, UK, ${ }^{3}$ Health Sciences Center, Perinatal Research Center, University of Colorado, Aurora, Colorado 80010, USA and ${ }^{4}$ Colorado State University, Fort Collins, Colorado 80523, USA

Correspondence should be addressed to $R$ G Lea who is now at School of Veterinary Medicine and Science, University of Nottingham, Sutton Bonington Campus, Sutton Bonington LE12 5RD, UK; Email: richard.lea@nottingham.ac.uk

\begin{abstract}
Overnourishing pregnant adolescent sheep promotes maternal growth but reduces placental mass, lamb birth weight and circulating progesterone. This study aimed to determine whether altered progesterone reflected transcript abundance for StAR (cholesterol transporter) and the steroidogenic enzymes (Cyp11A1, Hsd3b and Cyp17). Circulating and placental expression of ovine placental lactogen $(\mathrm{OPL})$ was also investigated. Adolescent ewes with singleton pregnancies were fed high $(\mathrm{H})$ or moderate (M) nutrient intake diets to restrict or support placental growth. Experiment 1: peripheral progesterone and oPL concentrations were measured in $\mathrm{H}(n=7)$ and $\mathrm{M}(n=6)$ animals across gestation (days 7-140). Experiment 2: progesterone was measured to mid- (day 81; M: $n=11, \mathrm{H}: n=13$ ) or late gestation (day 130; M: $n=21, \mathrm{H}: n=22$ ), placental oPL, StAR and steroidogenic enzymes were measured by $\mathrm{qPCR}$ and oPL protein by immunohistochemistry. Experiment 1: in $\mathrm{H}$ vs $\mathrm{M}$ animals, term placental $(P<0.05)$, total cotyledon $(P<0.01)$ and foetal size $(P<0.05)$ were reduced. Circulating oPL and progesterone were reduced at mid- $(P<0.001, P<0.01)$ and late gestation $(P<0.01, P<0.05)$ and oPL detection was delayed $(P<0.01)$. Experiment 2: placental oPL was not altered by nutrition. In day $81 \mathrm{H}$ animals, progesterone levels were reduced $(P<0.001)$ but not related to placental or foetal size. Moreover, placental steroidogenic enzymes were unaffected. Day 130 progesterone $(P<0.001)$ and $C y p 11 A 1$ $(P<0.05)$ were reduced in $\mathrm{H}$ animals with intrauterine growth restriction $(\mathrm{H}+\mathrm{IUGR})$. Reduced mid-gestation peripheral oPL and progesterone may reflect altered placental differentiation and/or increased hepatic clearance respectively. Restricted placental growth and reduced biosynthesis may account for reduced progesterone in day 130 H + IUGR ewes.

Reproduction (2007) 133 785-796
\end{abstract}

\section{Introduction}

During normal pregnancy in humans, ovarian-derived progesterone is initially important for pregnancy maintenance. However, as pregnancy progresses, the placenta becomes the main source of progesterone and thus compromised placental hormone secretion is a potential risk factor to pregnancy. This also applies to other mammals including the sheep (Al-Gubory et al. 1999). In human intrauterine growth restriction (IUGR), a majority of cases are associated with restricted placental growth (Heinonen et al. 2001). Although the causes of human IUGR are multifactorial, some studies have shown alterations in placental hormone levels, e.g. reduced progesterone and placental lactogen (Westergaard et al. 1984, Yanaihara et al. 1984). It is not clear, however, whether these changes arise as a result of impaired placental production and/or synthesis, or simply reflect reduced placental size.

Human adolescent pregnancies have an increased incidence of IUGR which has been associated with maternal growth and attributed to an endocrinemediated perturbation in nutrient partitioning between mother and foetus (Scholl \& Hediger 1993, Scholl et al. 1997). However, the precise intrauterine mechanisms that underlie IUGR during human adolescent pregnancy 
are ethically and practically difficult to determine. Although limited progress has been made from the study of human IUGR, the mechanistic basis of IUGR during adolescent pregnancy relies largely on the development of controlled animal models. In a sheep model of human adolescent pregnancy, adolescent ewes carrying singleton pregnancies are offered a normal or high intake $(2 \times$ maintenance) designed to maintain maternal adiposity or promote rapid maternal growth respectively. Paradoxically, those animals on the high dietary intake, despite showing increased adiposity, have significantly smaller lambs than the control animals (Wallace et al. 1996, 1997a). Restricted placental growth is central to the pathology of IUGR in this model and has been associated with altered maternal endocrine status including reduced levels of circulating progesterone from as early as day 50 of pregnancy (Wallace et al. 1997a, 1997b, 2001, 2003). These nutrition-driven effects only occur in growing adolescent sheep and foetal IUGR can be partly reversed by supplementation with progesterone from days 5 to 55 (Wallace et al. 2003, 2005a). In addition, the administration of growth hormone $(\mathrm{GH})$, also attenuated in high intake ewes, impacts on uteroplacental growth if given during the period of placental proliferation (Wallace et al. 2004). Interestingly, GH administration later in gestation (days 95-125) does not alter placental mass, but does affect maternal metabolism and induce a modest increase in foetal weight (Wallace et al. 2006a, 2006b). These observations suggest that the hormonal changes are likely mechanistic and important to the process of IUGR, particularly as they occur at midgestation prior to changes in placental or foetal size. The hormonal changes are accompanied by the developmental changes at the mid-gestation (day 81) maternalfoetal interface manifest by 1 ) reduced trophoblast proliferation, 2) increased placental bax protein indicative of apoptotic cell death and 3) reduced expression of several angiogenic growth factors (Lea et al. 2005, Redmer et al. 2005). The relationship between these developmental changes and alterations in placentalderived hormones such as progesterone is uncertain.

In a different sheep model of foetal IUGR where the trigger is exposure of an adult pregnant ewe to hyperthermia, circulating ovine placental lactogen (OPL) concentrations were reduced but placental $\mathrm{OPL}$ mRNA levels remained unchanged (Regnault et al. 1999). Consequently, the mechanism was thought to reflect a problem in placental differentiation affecting oPL release. Sheep have a cotyledonary, syneptheliochorial placenta (Fig. 1A). The foetal trophectoderm layer comprises uninucleate proliferative cells and a population of binucleate trophoblast cells (BNCs; Hoffman \& Wooding 1993). These non-proliferative BNCs comprise about $15 \%$ of the trophectoderm and are formed from the adjacent uninucleate trophectoderm cells by a process of nuclear division without

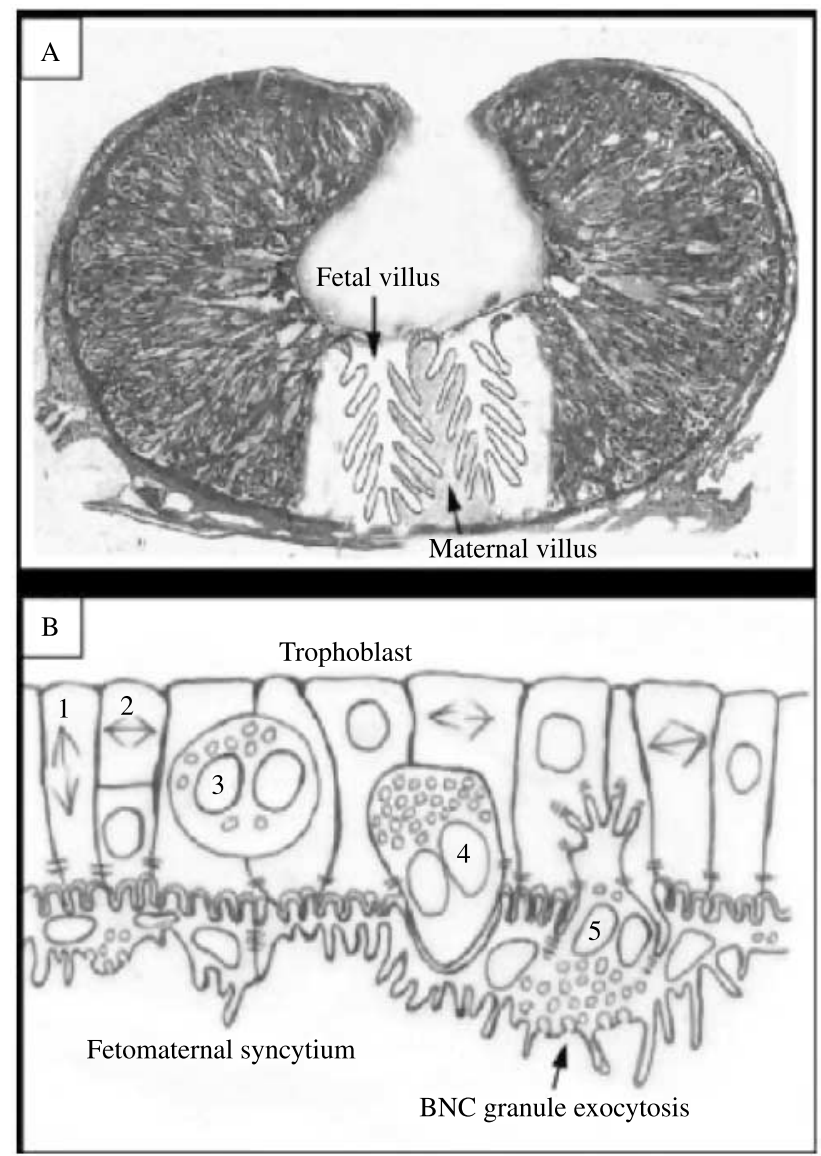

Figure 1 Diagram of the ovine placentome. (A) Transverse section through the centre of a sheep placentome with a diagrammatic inset showing the way the maternal and the foetal villi are interdigitated. (B) The ovine maternal-foetal interface where the trophoblast containing the binucleate cells (BNCs) is apposed to the maternal foetal syncytium. The uninucleate trophoblast cells form the binucleate cells by division without cytokinesis $(1,2)$. The binucleate cells form the syncytium by migration $(3,4)$ and fusion initially with the uterine epithelial cells $(4)$ and latterly with the persistent syncytium (5).

cytokinesis (Hoffman \& Wooding 1993). BNCs become rounded in appearance and form granules containing $\mathrm{OPL}$ and other protein products. The BNCs then migrate from the trophectoderm layer and fuse with maternal epithelial cells to form a maternal-foetal hybrid syncytium. Following fusion, the oPL-containing granules translocate to the basal plasmalemma of the syncytium and $\mathrm{OPL}$ is released into the maternal compartment by exocytosis (Fig. 1B). Consequently, $\mathrm{OPL}$ secretion to the maternal circulation is entirely dependent on BNC migration, which occurs from as early as day 16 of pregnancy (Wooding 1981, Wooding et al. 1986, 1996). BNC migration and fusion is also essential for placental differentiation, so any factors that interfere with this process may also alter placental lactogen secretion.

Secretion of progesterone by diffusion is coincident with its synthesis; there is no storage organelle. In the 
sheep, the placenta is the main site of progesterone synthesis and no corpus luteum progesterone is required post 50 days (Al-Gubory et al. 1999). The cellular location of placental progesterone synthesis is however controversial. Studies of isolated ovine and bovine binucleate cells demonstrate progesterone synthesis independent of uninucleate trophectodermal cells (Wango et al. 1991). However, immunocytochemistry of 3B-hydroxysteroid dehydrogenase (encoded by $\mathrm{Hsd} 3 \mathrm{~b}$ ) in the ewe (Riley et al. 1991) and cytochrome P450scc (encoded by Cyp11A1) in the cow (Ullman \& Reimers 1989) indicate that uninucleate cells have the enzymes and not the binucleate cells.

Reduced maternal progesterone levels may reflect decreased placental synthesis. At the intracellular level, the rate-limiting step in progesterone synthesis is the conversion of cholesterol to pregnenolone by cytochrome P450scc. This occurs in trophoblast mitochondria and is followed by the conversion of pregnenolone to progesterone by type $13 \beta$-hydroxysteroid dehydrogenase (Strauss et al. 1996). In addition, progesterone synthesis depends on the transport of cholesterol from the outer to the inner mitochondrial membrane where cytochrome P450scc is localised, and this is controlled by the transporter, StAR (reviewed in Tuckey 2005). Once progesterone is produced, it can be converted to androgen (androstenedione) by cytochrome P450c17 that can then be converted to oestrogens by placental aromatase. Consequently, a decrease in placental progesterone production may be associated with increased cytochrome P450c17 (Mason et al. 1989).

In the sheep model of adolescent pregnancy, we investigated 1) potential mechanisms which may underlie reduced maternal levels of progesterone and 2) circulating and placental levels of oPL. We hypothesised that in overnourished adolescent sheep, reduced progesterone may be due to altered placental biosynthesis. Consequently, we have investigated the abundance of RNA transcripts for 1) the cholesterol transporter StAR, 2) the steroidogenic enzymes Cyp11A1 and $H s d 3 b$ critical for progesterone synthesis and 3 ) Cyp17 (encoding cytP450c17) as a possible mediator of progesterone breakdown. Placental oPL transcript abundance and immunoexpression were also measured and compared with the levels measured in the maternal circulation.

\section{Materials and Methods}

\section{Animals and experimental design}

All procedures were licensed under the UK Animals (Scientific Procedures) Act of 1986. Embryos recovered on day 4 after oestrus from superovulated adult ewes (Border Leicester $\times$ Scottish Blackface) that had been inseminated by a single sire (Dorset Horn) were synchronously transferred, singly, into the uteri of adolescent recipient ewe lambs (Dorset Horn $\times$ Mule) as previously described (Wallace et al.1997a, 1999). The average age of the peripubertal recipient ewe lambs was $190 \pm 5$ (experiment 1 ) and $225 \pm 3$ days (experiment 2 ). This protocol ensured that placental and/or foetal growth was not influenced by varying foetal number or partial embryo loss. In addition, the use of a single sire and a limited number of donors maximised the homogeneity of the resulting foetuses. All animals were housed in individual pens under natural lighting conditions $\left(57^{\circ} \mathrm{N}\right.$ $2^{\circ} \mathrm{W}$ ). Immediately after embryo transfer, the adolescent ewes were allocated to one of the two dietary treatments, so that the two groups were similar with respect to live weight, body condition score (BCS; Rusell et al. 1969) and ovulation rate determined at the time of laparoscope-aided embryo transfer. Within individual studies, care was also taken to balance for donor embryo source where possible. Recipient ewes were offered individually a high $(\mathrm{H})$ or a moderate $(\mathrm{M})$ level of a complete diet (Wallace et al. 1996). The aim was to achieve a rapid maternal growth rate of $250-300 \mathrm{~g} /$ day in the $\mathrm{H}$ group and to maintain a low growth rate of 50-75 g/day in the $M$ group, during the first 100 days of gestation. The moderate (control) dietary level aimed to maintain maternal adiposity and BCS throughout gestation and was predicted to optimise placental and foetal growth in this genotype. The complete diet provided an estimated 10.2 MJ metabolisable energy per kilogram dry matter (DM), $136.6 \mathrm{~g}$ crude protein per kilogram DM and had an average DM of $85.5 \%$. All ewes were offered their feed in two equal portions at 0800 and $1600 \mathrm{~h}$ daily and the daily feed refusal was weighed and recorded prior to the $0800 \mathrm{~h}$ feed. Moderate intake ewes were offered their experimental diets starting immediately after embryo transfer, while the level of feed offered to high intake ewes was increased gradually over a 2 -week period until the level of daily feed refusal was $\approx 15 \%$ of the total offered (equivalent to ad libitum intakes). Ewes were weighed weekly and their BCS was assessed monthly. The level of feed offered was adjusted thrice each week according to both live weight changes and feed refusals. At $\approx 50$ days of gestation, pregnancy was confirmed by transabdominal ultrasonography. After day 100 of gestation, the feed intake of the moderate intake group was adjusted weekly to maintain BCS and meet the increasing nutrient demands of the developing foetus.

In experiment 1, maternal peripheral progesterone and placental lactogen concentrations were measured in relation to placental and lamb birth weight at term (M: $n=6, \mathrm{H}: n=7$ ). Other data pertaining to these pregnancies have been published previously (Wallace et al. 1999). In experiment 2 , identically treated pregnant ewes from separate studies were killed at days 81 (M: $n=11, \mathrm{H}: n=13$ ) and 130 of gestation (M: $n=21$, $\mathrm{H}: n=22)$. Other data pertaining to the former study have been published previously (Lea et al. 2005). 


\section{Blood sampling and radioimmunoassays}

Blood samples were collected from all ewes by jugular venepuncture thrice a week (Monday, Wednesday and Friday) throughout gestation (experiment 1) or immediately prior to necropsy at day 81 or 130 (experiment 2). All samples were taken about $3 \mathrm{~h}$ after the morning feed. In experiment 1, plasma oPL concentrations, determined once weekly, were measured in duplicate by a homologous RIA procedure using a highly specific anti-oPL antibody (non-cross-reactive with ovine $\mathrm{GH}$ or ovine prolactin) as previously described by Kappes et al. (1992). The assay sensitivity was $100 \mathrm{pg} / \mathrm{tube}$. With a maximum volume of serum at $400 \mu \mathrm{l}$, this is equivalent to a sensitivity of $250 \mathrm{pg} / \mathrm{ml}$. We used serum between 10 and $400 \mu \mathrm{l}$ depending on gestational age and with respect to the individual assay runs described in this paper, consistent detection was observed at $100-150 \mathrm{pg} / \mathrm{ml}$. The intra- and inter-assay coefficients of variation for a high and low plasma quality control were 2.4 and $4.1 \%$, and 4.6 and $5.4 \%$ respectively. In experiments 1 and 2, plasma progesterone concentrations, determined thrice weekly or prior to necropsy, were measured in duplicate, as described by Ronayne \& Hynes (1990). The assay limit of detection was $0.05 \mathrm{ng} / \mathrm{ml}$ and the respective intra- and inter-assay coefficients of variation were 7.5 and $11.4 \%$ for experiment 1 , and 10.2 and $21.4 \%$ for experiment 2.

\section{Tissue collection and fixation}

Dams were killed by i.v. administration of an overdose of sodium pentobarbitone $(20 \mathrm{ml}$ Euthesate; $200 \mathrm{mg}$ pentobarbitone per millilitre; Willows Francis Veterinary, Crawley, UK) and exsanguination by severing the main blood vessels of the neck. The foetus was killed by intracardiac administration of sodium pentobarbitone ( $5 \mathrm{ml}$ Euthesate). The umbilical cord was clamped and the foetus dried and weighed. The uteri were dissected and ten representative placentomes removed from the entire length of the gravid uterine horn and weighed. Placentomes were then either frozen at $-80{ }^{\circ} \mathrm{C}$ for RNA extraction or sliced into $7 \mathrm{~mm}$ cross-sections and immersion fixed in 10\% neutral buffered formalin for $24 \mathrm{~h}$, followed by $70 \%$ ethanol prior to routine wax embedding. All remaining placentomes were weighed in order to calculate the total placentome weight.

\section{Placental RNA isolation}

RNA was extracted from frozen whole placentome tissue collected from 21 individual day 81 pregnancies (M: $n=11, \mathrm{H}: n=10$ ) and 31 individual day 130 pregnancies (M: $n=11, H$-IUGR: $n=8, H+$ IUGR: $n=12$ ). The tissue was pulverised and $50 \mathrm{mg}$ were added to $0.5 \mathrm{ml}$ lysis buffer containing guanidine isothiocyanate and 2-mercaptoethanol (Sigma lysis solution). The sample was then homogenised and RNA extracted according to the protocol supplied with the GenElute Mammalian Total RNA extraction kit (Sigma-Aldrich Inc.). The quality and quantity of total RNA were determined via capillary electrophoresis using an Agilent 2100 Bioanalyzer (Agilent technologies, Wilmingham, DE, USA).

\section{$R T$ and real-time PCR}

All reagents and procedures used for real-time RT-PCR were purchased from and used as directed by Applied Biosystems (Warrington, Cheshire, UK). Real-time PCR was performed using an ABI PRISM 7700 Sequence Detection System (Applied Biosystems). For each sample, $\approx 30 \mathrm{ng}$ total RNA was reverse transcribed in triplicate using TaqMan RT reagents and multiscribe reverse transcriptase. Ovine primer sequences (Table 1) were obtained either directly through collaboration $(H s d 3 b)$ from the literature $(\mathrm{OPL}, \mathrm{Cyp} 11 \mathrm{~A} 1)$ or by slight modification of published/available sequences from other species (StAR and cyclophilin respectively). Realtime RT-PCR was carried out using the SYBR green I nucleic acid stain, and the polymerisation and amplification reactions were carried out in triplicate using 96-well PCR plates. Five microlitres of cDNA were added to $20 \mu \mathrm{l}$ Master Mix and a final volume of $10 \mu \mathrm{l}$ added to the real-time plate. The plate was incubated in an ABI PRISM 7700 Sequence Detector (Applied Biosystems) under the following conditions: $50{ }^{\circ} \mathrm{C}$ for $2 \mathrm{~min}, 95^{\circ} \mathrm{C}$ for $10 \mathrm{~min}, 40$ cycles of $95^{\circ} \mathrm{C}$ for $15 \mathrm{~s}$ and $60^{\circ} \mathrm{C}$ for $1 \mathrm{~min}$. Quantification was determined using a relative standard curve method with different doses of a reference standard cDNA generated from RNA pooled

Table 1 Primers used for real-time PCR studies.

\begin{tabular}{|c|c|c|c|}
\hline Gene $^{a}$ & Forward primer $\left(5^{\prime}-3^{\prime}\right)$ & Reverse primer $\left(5^{\prime}-3^{\prime}\right)$ & Genbank accession no. \\
\hline Cyclophilin ${ }^{b}$ & САTTCTGAAGCATACAGGTCCTG & TCCATGGCTTCCACAATATT & AY251270 \\
\hline$O P L^{\mathrm{c}}$ & AGCAACAACGGTGGCTAACT & GCCATACTGTTCATCAAATCTGT & NM_001009309 \\
\hline$S t A R^{\mathrm{d}}$ & GGAGAGCCGGCAGGTCAATG & CTTCTGCAGGACCTTGATCTCCTTG & NM_001009243 \\
\hline Cyp11A ${ }^{\mathrm{e}}$ & AGAGAATCCACTTTCGCCACATC & GGTCTTTCTTCCAGGTTCCTGAC & K02130 \\
\hline$H s d 3 b^{f}$ & GTGACCGGAGGAGGAGG & AGGAAGCTCACTATTTCCA & X17614 \\
\hline Cyp $17^{\mathrm{e}}$ & TGATGATTGGACACCACCAGTTG & AGAGAGAGAGGCTCGGACAGATC & M12547 \\
\hline
\end{tabular}

${ }^{\mathrm{a}}$ Optimised primer concentrations were $300 \mathrm{nM}$. ${ }^{\mathrm{b}}$ Modified mouse sequences kindly supplied by Dr E Devinoy, INRA, Jouy-en-Josas, France.

cPublished ovine primers: Lacroix et al. (2002). ${ }^{\mathrm{d}}$ Modified from published porcine primer sequences: Rusovici et al. (2005). ${ }^{\mathrm{e}}$ Published ovine/bovine primers: Vaneslow et al. (2004). 'Bovine primer sequences for Hsd3b, kindly supplied by Dr B Mandon-Pepin, INRA. 
from eight day 81 placentomes $(4 \times M+4 \times H)$ or eight day 130 placentomes $(4 \times M+4 \times H)$. Individual placentome mRNA for each gene of interest was expressed relative to the housekeeping gene cyclophilin, which remained unaffected by treatment/group in subsequent studies. Primer concentrations were optimised prior to analysis (Table 1) and primer-dimer formation was excluded by running a melt curve for each primer pair. The mean coefficients of variation were oPL $(6.7 \%)$, StAR (9.6\%), Cyp11A1 (16.5\%), Hsd3b (9.2\%), Cyp17 (11.9\%) and cyclophilin (16.9\%).

\section{oPL Immunohistochemistry}

Placental sections $(5 \mu \mathrm{m})$ were mounted on poly-lysine coated slides (1 section/slide). Following routine dewaxing, antigen retrieval was carried out by microwaving the sections in $0.01 \mathrm{~mol} / \mathrm{l}$ citrate buffer $(\mathrm{pH} \mathrm{6.0)}$ on full power for $3 \times 5 \mathrm{~min}$. Sections were placed in a DAKO Autostainer and incubated with monoclonal rat anti-oPL (in-house antibody supplied and previously validated by Dr P Wooding: Wooding 1981) at the dilution of 1:3000 for $30 \mathrm{~min}$. Antibody binding was visualised using the ChemMate peroxidase/DAB detection system (DAKO, Ely, Cambridgeshire, UK) and all sections were counterstained using haematoxylin. Negative controls were performed by replacing the primary antibodies with rat serum (oPL IgG concentration unknown). Day 81 and 130 samples were run in separate experiments and at each gestational stage, all available sections were run simultaneously. From each animal, one placentome section was incubated with primary antibody and within an experiment, a selected number of sections were incubated with non-specific rat serum.

The oPL staining was quantified by computer-aided image analysis using a Zeiss Axioplan microscope (20X objective; Carl Zeiss Ltd, Welwyn Garden City, Herts, UK) and Hitachi HV-C20 colour camera (Hitashi Denshi, Tokyo, Japan) connected to a computer running Image Pro Plus software (Media Cybernetics, Silver Spring, MD, USA). Quantification was carried out over ten fields of view taken randomly and transversely across the central part of the placentome section (200X magnification $=4.2 \times 10^{5} \mu^{2}$; Fig. 3). On each captured image, the total number of positively stained areas (brown colour) was obtained as well as the percentage area stained. As an initial quality control step, brown-stained cells and regions were manually counted in ten fields of view from a single placentome. This was carried out by two independent observers ( $\mathrm{S} M$ and $\mathrm{KW}$ ). The image analysis system was then used to count the same areas and the results were found to be comparable $\left(P<0.001, R^{2}=0.83, n=10\right)$. Since some staining was observed in syncytial segments, the mean percentage area stained values were used for statistical analysis.

\section{Statistical analysis}

For the day 130 cohort, IUGR was defined on the basis of foetal weight $(\mathrm{IUGR}=$ weight $<$ mean $-2 \times$ s.D. of control group; Robinson et al. 1979). Image analyses data were analysed using Genstat or Excel software. Data were tested for normal distribution and groups compared by one-way ANOVA and standard post hoc t-tests where appropriate. Where data were not normally distributed, a non-parametric Mann-Whitney test was used. Regression analysis was used to investigate potential sets of correlating data and where necessary, interactions between two variables were investigated after allowing for the effect of diet.

\section{Results}

\section{Experiment 1}

\section{Pregnancy outcome}

As reported for these pregnancies previously (Wallace et al. 1999), a high compared with a moderate dietary intake throughout pregnancy resulted in a major reduction in placental weight $(258 \pm 33.5$ vs $457 \pm$ $75.1 \mathrm{~g}, P<0.05)$ and foetal cotyledon weight $(56 \pm 6.1$ vs $133 \pm 21.1 \mathrm{~g}, P<0.01)$ at term. This, in turn, was associated with a decrease $(-38 \%)$ in lamb birth weight $(3030 \pm 340$ vs $4940 \pm 570 \mathrm{~g}, P<0.05)$.

\section{Effects of nutrition on maternal oPL concentrations across gestation}

Maternal plasma oPL concentrations throughout gestation are illustrated in Fig. 2A. Compared with moderately fed controls (M: $n=6)$, animals on the high nutrient intake diet $(\mathrm{H}: n=7)$ exhibited lower levels of plasma oPL across gestation with levels significantly diverging at day 51 $(P<0.05)$ and for the remainder of pregnancy (days 58-105: $21.5 \pm 4.0$ vs $7.6 \pm 0.7 \mathrm{ng} / \mathrm{ml}, P<0.003$; days 111-146: $83.4 \pm 16.1$ vs $25.1 \pm 4.3 \mathrm{ng} / \mathrm{ml}, P<0.02$; Student's $t$-test on log-transformed data). oPL was also detected later in the high intake group than in the controls. For example, $\mathrm{H}$ group animals exhibited a 7 -day delay in the rise of plasma oPL above a threshold of $0.5 \mathrm{ng} / \mathrm{ml}$ (55.5 \pm 1.5 vs $48.0 \pm 1.86$ days; $P<0.01$ by Student's t-test).

Regression analysis of log-transformed mean plasma oPL concentrations across gestation (9-139 days) and adjusting for diet effects revealed a positive association with placental weight $\left(P<0.05, R^{2}=0.36, n=12\right)$ and foetal weight $\left(P<0.05, R^{2}=0.34, n=13\right)$. Moreover, mean $\log \mathrm{OPL}$ values across the final third of gestation (111-139 days) also positively associated with placental weight $\left(P<0.01, R^{2}=0.65, n=12\right)$, cotyledon weight $\left(P<0.01, R^{2}=0.65, n=12\right)$ and foetal weight $(P<0.001$, $\left.R^{2}=0.74, n=13\right)$. 


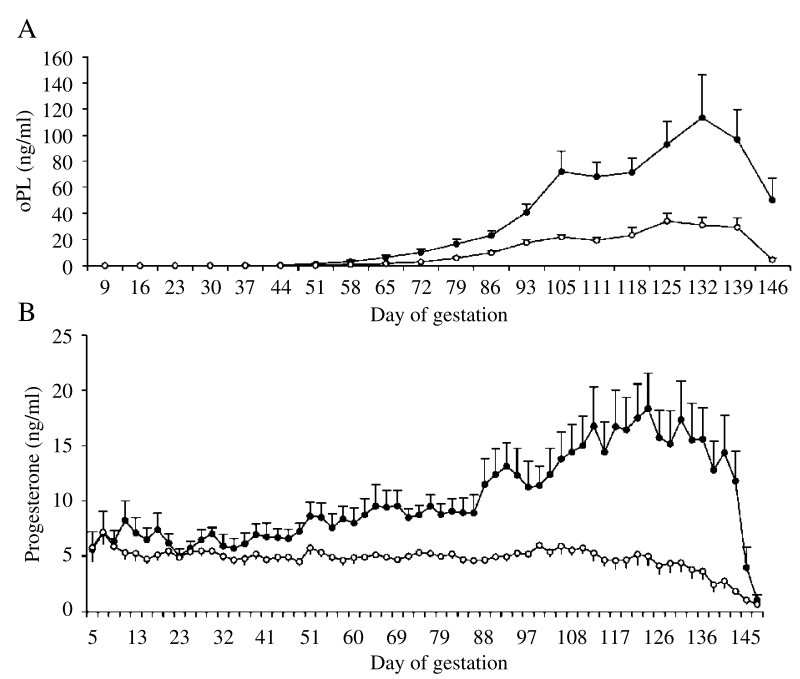

Figure 2 Changes in maternal peripheral ovine placental (A) lactogen and (B) progesterone across gestation in animals on a control moderate nutrient intake diet $(\bullet)$ and on a high nutrient intake diet $(O)$. Progesterone was measured thrice weekly and oPL once weekly across gestation.

\section{Effects of nutrition on maternal progesterone across gestation}

Figure $2 \mathrm{~B}$ shows maternal plasma progesterone concentrations determined from blood samples taken thrice a week until term. Mean ovulation rates at embryo transfer were $2.0 \pm 0.5$ and $2.7 \pm 0.4$ corpora lutea for the moderate $(n=6)$ and high intake $(n=7)$ animals respectively, and there was no significant difference between the groups. During the first third of pregnancy (13-48 days), overall mean progesterone concentrations were not significantly different between $M$ and $H$ animals. However, the mean progesterone concentrations for the middle and final thirds of gestation were significantly lower in $\mathrm{H}$ intake animals than in $\mathrm{M}$ controls (days $51-105: 5.1 \pm 0.3$ vs $10.0 \pm 1.3 \mathrm{ng} / \mathrm{ml}$, $P<0.01$; days 108-138: $4.5 \pm 0.7$ vs $15.8 \pm 2.8 \mathrm{ng} / \mathrm{ml}$ : $P<0.01$; Student's $t$-test on log-transformed data).

In the first third of gestation (13-48 days), there were no significant correlations between maternal plasma progesterone concentrations and placental weight, cotyledon weight or foetal weight. Regression analysis of log-transformed mean progesterone concentrations across the middle third of gestation (days 51-105) after adjusting for diet effects revealed a significant positive association with placental weight $\left(P<0.05, R^{2}=0.62\right.$, $n=13)$ and total foetal cotyledon weight $(P<0.05$, $\left.R^{2}=0.77, n=13\right)$. Across the final third of gestation (days 108-138), log plasma progesterone concentrations positively associated with placental weight $(P<0.05$, $\left.R^{2}=0.45, \quad n=13\right)$, total foetal cotyledon weight $\left(P<0.05, \quad R^{2}=0.58, \quad n=13\right)$ and foetal weight $\left(P<0.01, R^{2}=0.51, n=13\right)$.
During the first third of gestation, there was no significant association between maternal progesterone and oPL concentrations. However, during the middle third of gestation (progesterone: 51-105 days vs oPL: 58105 days), progesterone was significantly and positively associated with oPL after adjusting for diet $(P<0.05$, $\left.R^{2}=0.63, n=13\right)$. During the final third of gestation, a significant relationship was suggested since the $P$ value fell just outside the $5 \%$ level $\left(P=0.056, R^{2}=0.65, n=13\right)$.

\section{Experiment 2}

\section{Maternal live weight and body condition}

Embryo transfers carried out on days 81 and 130 were separate studies. In the day 81 study, at embryo transfer, the mean live weight and BCSs were $45 \pm 0.8$ vs $46 \pm$ $0.9 \mathrm{~kg}$ and $2.3 \pm 0.04$ vs $2.4 \pm 0.04$ score units in the $\mathrm{H}$ $(n=13)$ and $\mathrm{M}(n=11)$ group respectively. In the day 130 group, at embryo transfer, the mean live weight and BCSs were $44 \pm 0.8$ vs $46 \pm 0.8 \mathrm{~kg}$ and $2.3 \pm 0.03$ vs $2.3 \pm 0.04$ score units in the $\mathrm{H}(n=22)$ and $\mathrm{M}(n=21)$ groups respectively. The diet-induced changes in maternal weight and BCS in day 81 and 130 cohorts in relation to placental and foetal weight at necropsy are shown in Table 2. Mean maternal live weight gain (g/day) and BCSs were significantly increased in the ad libitum fed $\mathrm{H}$ group relative to the $M$ intake control group $(P<0.001)$ as determined at both gestational time-points.

At day 81 of gestation, total placentome weights were not significantly different. Nine and seven foetuses were male in the $\mathrm{H}$ and $\mathrm{M}$ groups respectively, and there was no difference in foetal weight between nutritional groups. In contrast, at day 130 of gestation, both placental and foetal weight were significantly reduced $(P<0.0001)$ in the $\mathrm{H}$ when compared with the $\mathrm{M}$ group (Table 2). Fourteen foetuses were male in both the $\mathrm{H}$ and the $\mathrm{M}$ groups at this time-point.

The late gestation $\mathrm{H}$ group was further divided into ewes with IUGR foetuses (H+IUGR) and less perturbed animals (H-IUGR). By one-way ANOVA, placental and foetal size was significantly affected across the three groups $(P<0.0001)$. The H+IUGR group $(n=14)$ had significantly smaller placentas than the $\mathrm{H}-$ IUGR group $(n=8 ; P<0.01$, post hoc $t$-test) and the control M group animals $(n=21 ; P<0.0001$, post hoc t-test; $216.29 \pm$ $18.99,356.38 \pm 43.99$ and $458.24 \pm 28.69$ g respectively). Similarly, foetal weight was significantly reduced in the H+IUGR group when compared with the $\mathrm{H}-\mathrm{IUGR}$ group $(P<0.001$, post hoc $t$-test $)$ and the control $M$ animals $(P<0.0001$; post hoc $t$-test; $2900.50 \pm 203.06,4181.38 \pm 157.06$ and $4525.71 \pm$ $90.83 \mathrm{~g}$ respectively). As previously reported (Wallace et al. 2000, 2002, 2006b), the IUGR observed was asymmetric since foetal brain/liver weight ratios were significantly affected across the three late gestation groups $(P<0.001$, one-way ANOVA) and significantly 
Table 2 Maternal live weight gain to necropsy and body condition score (BCS) in relation to mid- (day 81) and late gestation (day 130) placental and foetal weights.

\begin{tabular}{|c|c|c|c|c|c|c|}
\hline & \multicolumn{2}{|c|}{ Day 81} & \multirow{2}{*}{$\begin{array}{c}\text { Significance } \\
M \text { vs H }\end{array}$} & \multicolumn{2}{|c|}{ Day 130} & \multirow{2}{*}{$\begin{array}{c}\text { Significance } \\
M \text { vs H }\end{array}$} \\
\hline & M & $\mathrm{H}$ & & M & $\mathrm{H}$ & \\
\hline $\mathrm{N}$ & 11 & 13 & - & 21 & 22 & - \\
\hline Live weight gain (g/day) & $64.7 \pm 4.2$ & $274.6 \pm 15.3$ & $P<0.0001$ & $49 \pm 4.2$ & $228 \pm 8.8$ & $P<0.0001$ \\
\hline BCS at necropsy & $2.2 \pm 0.0$ & $2.8 \pm 0.0$ & $P<0.0001$ & $2.3 \pm 0.0$ & $3.3 \pm 0.1$ & $P<0.001$ \\
\hline Placental weight (g) & $645 \pm 40.5$ & $685 \pm 54.5$ & NS & $458 \pm 28.7$ & $267 \pm 24.3$ & $P<0.0001$ \\
\hline Foetal weight $(\mathrm{g})$ & $417 \pm 9.1$ & $439.2 \pm 13.1$ & NS & $4526 \pm 90.8$ & $3366 \pm 193.2$ & $P<0.0001$ \\
\hline
\end{tabular}

All data pertain to experiment 2 . Values are mean \pm s.E.M.

increased in the IUGR group ( $M$ vs $\mathrm{H}-$ IUGR vs H+IUGR: $0.32 \pm 0.01$ vs $0.34 \pm 0.02$ vs $0.51 \pm 0.05$ respectively, $P<0.05$; post hoc $t$-test). The mean maternal live weight gain of the H+IUGR group was not significantly different from that of the H-IUGR group (282.24 \pm 16.85 and $272.14 \pm 10.57 \mathrm{~g} /$ day respectively), and adiposity scores at necropsy were equivalent $(3.3 \pm 0.13$ and $3.3 \pm 0.08$ score units respectively).

\section{Effects of nutrition on placental oPL mRNA}

Placental oPL mRNA was confirmed by real-time PCR using ovine-specific primers (Table 1). Comparison of $M$ and $\mathrm{H}$ groups at days 81 and 130 of gestation showed no significant effect of nutrition on placental oPL transcript abundance when expressed relative to cyclophilin (day $81 \mathrm{M}$ vs $\mathrm{H}: 0.79 \pm 0.09$ vs $0.61 \pm 0.08$ respectively; day $130 \mathrm{M}$ vs $\mathrm{H}-$ IUGR vs H+IUGR: $1.93 \pm 0.10$ vs $2.00 \pm$ 0.23 vs $1.77 \pm 0.17$ respectively). Similarly, there were no significant differences in the transcript abundance of the gene per se (analysed independently; data not shown) and the abundance of cyclophilin transcripts was not affected by treatment at either day 81 or 130 (data not shown).

\section{Effects of nutrition on placental oPL protein}

In all placental samples examined, OPL was localised to the binuclear cell population at the maternal foetal interface and, particularly evident in late gestation, to areas of syncytium where BNC fusion had recently occurred (Fig. 3A, day $81 ; 3 \mathrm{~B}$, day 130 ). There were no significant differences attributed to maternal nutritional treatment in the placental $\mathrm{OPL}$ protein expression at either day 81 ( $M$ vs H: $3.2 \pm 0.5$ vs $2.6 \pm 0.3$ ) or day 130 ( $M$ vs H: $6.6 \pm 1.0$ vs $5.4 \pm 4.2$ ). This remained consistent following subdivision of the late gestation $\mathrm{H}$ animals into $\mathrm{H}-\mathrm{IUGR}$ and $\mathrm{H}+\mathrm{IUGR}$ subgroups $(5.4 \pm 1.5$ vs $5.4 \pm$ 1.1 respectively). At late gestation, placental oPL staining was positively associated with placental weight when all groups were analysed together $\left(P<0.01, R^{2}=0.20\right.$, $n=43)$, in the moderate group $\left(P<0.05, R^{2}=0.22\right.$, $n=21)$ and in the combined $H$ group $(P<0.05$,
$R^{2}=0.17, n=22$ ). There was no correlation between $\mathrm{oPL}$ protein and foetal weight in any group.

\section{Effects of nutrition on maternal progesterone}

As presented in detail for experiment 1, maternal peripheral progesterone concentrations were significantly reduced at mid- and late gestation in $\mathrm{H}$ when compared with $M$ dams $(P<0.01$ and $P<0.001$ respectively; Table 3 ). In the late gestation cohort, subdivision of the $\mathrm{H}$ group on the basis of foetal weight revealed that maternal progesterone was significantly affected across the three late gestation groups $(P<0.0001$; one-way ANOVA) and was significantly lower in those animals with IUGR (H+IUGR) when

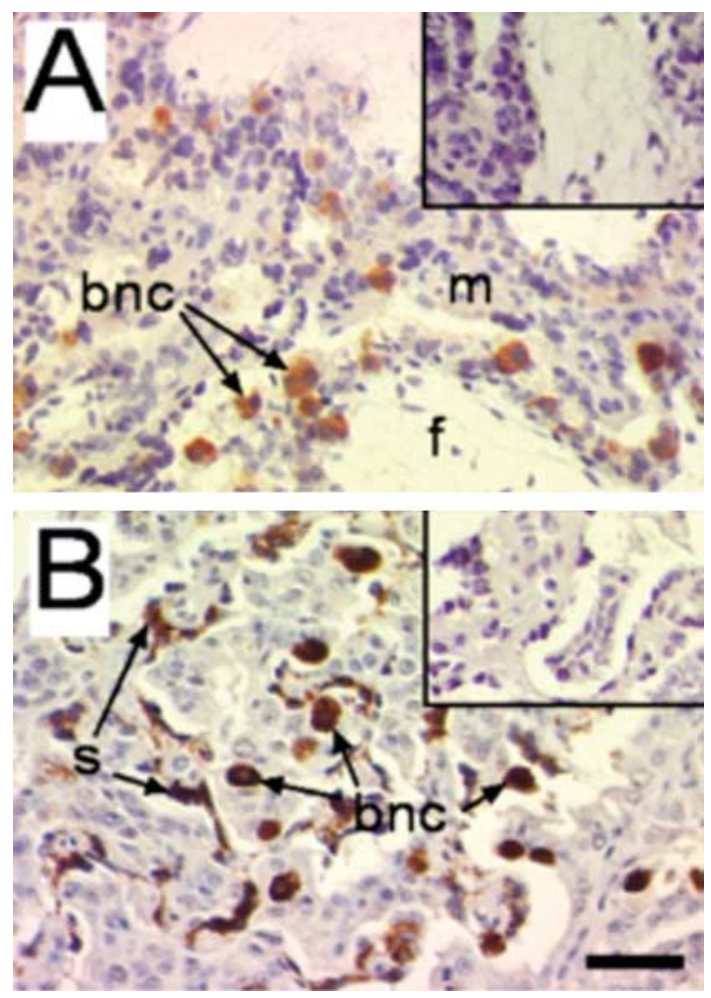

Figure 3 Immunolocalisation of ovine placental lactogen (oPL) in the ovine placentome. oPL was localised to the binuclear cells and maternal-foetal hybrid syncytium (s). (A) Day 81, (B) day 130. m, maternal caruncle; $f$, foetal cotyledon; bnc, binuclear cell. Scale bar $=100 \mu \mathrm{m}$. Inset, rat serum negative control. 
Table 3 Circulating maternal progesterone concentrations prior to necropsy in mid- and late gestation adolescent sheep.

\begin{tabular}{lccc}
\hline Progesterone $(\mathrm{ng} / \mathrm{ml})$ & $\mathbf{M}$ & H & Significance \\
\hline Day 81 & $9.05 \pm 1.76$ & $3.51 \pm 0.30$ & $P<0.01$ \\
Day 130 & $22.01 \pm 1.63$ & $11.26 \pm 1.88$ & $P<0.001$
\end{tabular}

Ewes were offered a moderate $(M)$ or high $(H)$ nutrient intake diet from embryo transfer (day 0) to slaughter at day 81 or 130.

compared with the $M(P<0.0001$ : post hoc $t$-test $)$ and $\mathrm{H}-$ IUGR $(P<0.01)$ groups (Fig. 4$)$.

Maternal progesterone was positively associated with placental weight when all groups were combined $\left(P<0.0001, R^{2}=0.42, n=43\right)$ in the moderate group $\left(P<0.05, R^{2}=0.25, n=21\right)$ and in the combined $\mathrm{H}$ group $\left(P<0.05, R^{2}=0.19, n=22\right)$. Similarly, progesterone was positively associated with foetal weight when all groups were combined $\left(P<0.0001, R^{2}=0.50\right.$, $n=43)$ in the combined $\mathrm{H}$ group $\left(P<0.001, R^{2}=0.43\right.$, $n=22)$ and in the H+IUGR group independently $\left(P<0.05, R^{2}=0.42, n=14\right)$.

Transcript abundance of StAR, Cyp11A1, Hsd3b and Cyp17 in mid- (day 81) and late gestation (day 130) placentomes

Placental RNA transcripts for StAR, Cyp11A1, Hsd3b and Cyp17 were detected in both mid- and late gestation placental samples. At day 81, there was no significant difference between the $\mathrm{M}$ and the $\mathrm{H}$ groups for StAR or any of the steroidogenic enzyme mRNA measured ( $M$ vs $\mathrm{H}$ for StAR: $0.47 \pm 0.06$ vs $0.46 \pm 0.05$, Cyp11A1: $4.89 \pm 0.68$ vs $6.48 \pm 0.61, H s d 3 b: 0.63 \pm 0.04$ vs $0.74 \pm 0.09$, Суp 17: $0.66 \pm 0.08$ vs $0.84 \pm 0.18$ ). Placental transcript abundance for Cyp11A1 was significantly affected across the three late gestation groups $(P<0.05$; one-way ANOVA) and was lower in the H+IUGR group

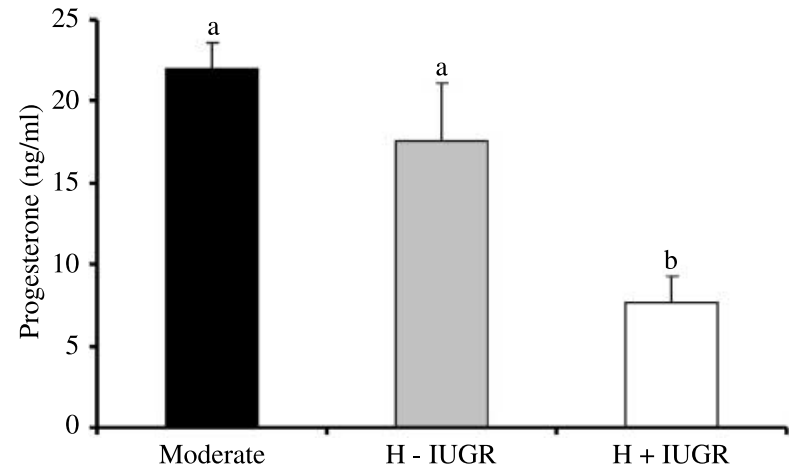

Figure 4 Circulating maternal progesterone concentrations prior to necropsy in late gestation adolescent sheep. Ewes were offered a moderate $(M)$ or high $(H)$ nutrient intake diet from embryo transfer (day 0 ) to slaughter at day 130 . The late gestation $\mathrm{H}$ group was further divided into ewes with IUGR foetuses (H+IUGR) and less perturbed animals ( $\mathrm{H}-\mathrm{IUGR})$. Different superscripts indicate significant differences between groups (post hoc $t$-test: $P<0.001$ ). when compared with the $M(P<0.01$ : post hoc $t$-test $)$ and the $\mathrm{H}-$ IUGR $(P<0.01)$ groups (Table 4$)$. Late gestation placental mRNAs for StAR, Hsd3b and Cyp17 were independent of nutrition and foetal growth status. Data expressed relative to the control cyclophilin gene and calculated independently (data not shown) showed similar results.

In late gestation (day 130) animals, maternal progesterone significantly correlated with the expression of placental Cyp11A1 $\left(P<0.05, R^{2}=0.18, n=31\right)$ and Hsd3b $\left(P<0.05, R^{2}=0.17, n=31\right)$. A significant correlation between maternal progesterone and $H s d 3 b$ was also observed in the H+IUGR subgroup $(P<0.05$, $R^{2}=0.42, n=12$ ). In contrast, mid-gestation (day 81) progesterone concentrations did not correlate with Cyp11A1, Hsd3b or Cyp17.

\section{Discussion}

It has previously been reported that pregnant adolescent ewes carrying singleton foetuses and offered a high intake diet throughout pregnancy have significantly smaller lambs at birth (Wallace et al. 1996, 1997a). This is due to reduced placental mass in the final third of gestation limiting nutrient transfer from mother to foetus. These pregnancies are also associated with reduced maternal levels of the placental-derived hormone, progesterone (Wallace et al. 1997a, 2003), from as early as day 50 of pregnancy. The results reported here confirm these data and furthermore demonstrate that placental lactogen concentrations are similarly reduced during the middle and final thirds of pregnancy. To determine whether these systemic changes reflect changes in placental genes key to the synthesis of these hormones, we have examined mid- and late gestation placental tissue for evidence of altered expression of oPL and the steroidogenic enzymes necessary for progesterone biosynthesis.

Data presented here illustrate that despite the dramatic reduction in systemic oPL in response to altered maternal nutrition, there is no accompanying reduction in placental oPL mRNA or protein at day 81 or 130 of gestation. Similarly, with respect to progesterone, there was no alteration in StAR or the steroidogenic enzymes at day 81 . However, at day 130 , the most perturbed $\mathrm{H}$ intake ewes with IUGR showed a reduction in the abundance of Cyp11A1 transcripts. In contrast, StAR and $H s d 3 b$ were unaffected as was the expression of Cyp17 that converts progesterone to androstenedione. These data suggest that at mid-gestation, reduced concentrations of $\mathrm{OPL}$ and progesterone in the peripheral maternal circulation do not reflect changes in placental oPL expression or the expression of StAR and the steroidogenic enzymes necessary for progesterone synthesis. Moreover, these endocrine changes do not reflect placental size since this is equivalent in both groups at this mid-gestation time-point. We propose 
Table 4 The expression of StAR and steroidogenic enzyme mRNA in placentomes from late gestation (day 130) adolescent ewes.

\begin{tabular}{lllll}
\hline Gene (ratio to cyclophilin) & \multicolumn{1}{c}{ M } & H-IUGR & H+IUGR & Significance \\
\hline StAR & $1.26 \pm 0.17$ & $1.23 \pm 0.06$ & $1.05 \pm 0.07$ & $\mathrm{NS}$ \\
Cyp11A1 & $0.12 \pm 0.01^{*}$ & $0.11 \pm 0.01^{*}$ & $0.08 \pm 0.01^{+}$ & \\
Hsd3b & $0.16 \pm 0.01$ & $0.15 \pm 0.01$ & $0.14 \pm 0.01$ & $\mathrm{NS}$ \\
Cyp17 & $0.06 \pm 0.01$ & $0.06 \pm 0.01$ & $0.04 \pm 0.01$ & $\mathrm{NS}$ \\
\hline
\end{tabular}

Ewes were individually offered either a moderate $(\mathrm{M})$ or high $(\mathrm{H})$ nutrient intake diet calculated to promote a normal or a rapid maternal growth rate respectively. Late gestation ewes with IUGR foetuses (foetal weight $<$ mean $-2 \times$ standard deviation of M group) were categorised (H+IUGR) and compared with both the less perturbed high intake (H-IUGR) and moderate groups. Data were analysed following adjustment for the control cyclophilin gene and represented as mean \pm S.E.M. ${ }^{*,+}$ Different superscripts denote significance differences as calculated by one-way ANOVA.

therefore that the mid-gestation reduction in maternal OPL may reflect altered BNC trophoblast fusion and/or the altered control of granule exocytosis subsequently affecting hormone release. With respect to the midgestation reduction in progesterone, we postulate that this likely reflects increased maternal metabolic clearance by the liver. However, in late gestation, reduced maternal progesterone in animals with IUGR partly reflects reduced placental size, but is also associated with reduced progesterone biosynthesis due to decreased Cyp11A1 mRNA. Although StAR and Hsd3b were not altered in this study, they were expressed in all placentas examined thus confirming previous reports (Su et al. 2004, Vaneslow et al. 2004). The lack of an effect of nutrition on placental Cyp17 indicates that increased progesterone breakdown is an unlikely explanation for reduced circulating steroid.

Reduced circulating OPL concentrations with no change in placental oPL mRNA or protein have been previously reported in a sheep model of placental insufficiency and foetal IUGR induced by maternal hyperthermia (Regnault et al. 1999). In this model, pregnant adult ewes were exposed to high ambient temperatures during the first and second thirds of gestation (Bell et al. 1987, Thureen et al. 1992) and, similar to the adolescent model, both oPL and progesterone concentrations were reduced at mid-gestation (day 93) with no significant reduction in placental size (Regnault et al. 1999). In contrast to the adolescent model, foetal size was reduced at day 93, and this is thought to reflect the greater severity of hyperthermia, when compared with altered nutrition, as a stimulus for IUGR (Wallace et al. 2005b). Notwithstanding, it is possible that the mechanism of reduced circulating $\mathrm{OPL}$ levels may be the same in both models. Indeed, the present study used the same RIA as the hyperthermia model and therefore both studies used the same highly specific and non-cross-reactive anti-oPL antibody (Kappes et al. 1992). With respect to the importance of OPL for foetal development, there is evidence that placental lactogen infused directly into the late gestation ovine foetus has subtle effects on some major organ systems (Schoknecht et al. 1996). However, it is recognised that a direct role in the induction of foetal IUGR requires further investigation.
Placental oPL release into the maternal circulation depends on the migration of BNCs and fusion with the maternal epithelium. However, the total amount detectable in the circulation will also be influenced by placental mass. In experiment 1, late gestation maternal oPL concentrations were reduced by $69 \%$ (days 111-146), whereas term placental size was reduced by $43 \%$. Therefore, it follows that the reduced concentration of oPL in the maternal circulation likely reflects both reduced placental mass and impaired trophoblast migration subsequently affecting hormone release following BNC fusion. In addition to lower levels of oPL in high nutrient intake animals, the gestational rise above a minimal threshold is delayed by at least 7 days. The reason for this is likely developmental and may also relate to inadequate BNC migration and fusion. In support of these possibilities, day 80 pregnant adolescent sheep on high nutrient intake diets exhibit reduced proliferative activity of the foetal trophectoderm accompanied by an increased expression of the pro-apoptotic protein bax (Lea et al. 2005). This indicates an altered proliferation/ apoptosis balance in the placenta which could affect trophoblast cell migration and fusion. Interestingly, pregnancy-specific protein B (PSPB) is also released from BNC granules and shows similar changes to oPL in response to high intake in the adolescent model (Wallace et al. 1997b, Green et al. 2000). Therefore, it follows that PSPB may be similarly affected by BNC migration and fusion.

In contrast to oPL release, progesterone secretion occurs by diffusion from ovine trophoblast cells. Enriched BNCs have been shown to synthesise progesterone from pregnenolone and uninucleate trophoblast plus the syncytium are reported to be immunopositive for $3 \beta$-hydroxysteroid dehydrogenase essential for progesterone biosynthesis (Riley et al. 1991, Wango et al. 1991). Consequently, progesterone will be released into both the foetal and the maternal circulations from trophoblast cells.

During ovine pregnancy, the placenta becomes the predominant source of progesterone from $\approx$ day 50 of gestation (Al-Gubory et al. 1999). Indeed, although the corpus luteum in the ewe persists until near term, it has been calculated that the late gestation placenta produces 
five times as much progesterone as the ovary (Linzell \& Heap 1968). Since there was no nutritional effect on circulating progesterone during the first 50 days of pregnancy, i.e. prior to the luteo-placental shift, it is likely that the $50 \%$ decline seen in late gestation is attributable to a dietary effect on placental rather than corpus luteum-derived progesterone. Notwithstanding, a modest effect of diet on ovarian progesterone cannot be ruled out. The rate-determining step in the synthesis of progesterone is the conversion of cholesterol to pregnenolone by cytochrome P450scc (Tuckey 2005). Consequently, reduced progesterone in the late gestation high nutrient intake group with IUGR may be consequential to reduced Cyp11A1 encoding cytochrome P450scc in the same subgroup. However, since Cyp11A1 was not altered earlier in gestation, despite reduced circulating levels of progesterone, the reduction in late gestation is likely a consequence of rather than a cause of IUGR. Therefore, it follows that these changes must follow events occurring earlier in gestation. In support of this, mid-gestation alterations in the placental expression of angiogenic factors have been linked to a reduction in absolute uteroplacental blood flow in late gestation (Wallace et al. 2002, Redmer et al. 2005). Since, in the human, an increase in progesterone production during pregnancy has been associated with an increased blood supply to the placenta (reviewed in Tuckey 2005), altered placental endocrine function in the overnourished adolescent sheep may partially reflect developmental/vascular abnormalities occurring earlier in gestation.

Increased feed intake in non-pregnant adult sheep decreases circulating progesterone and increases blood flow in the liver and hepatic portal vein (Burrin et al. 1989, Parr 1992, Parr et al. 1993). The liver is the major site of progesterone inactivation and Parr et al. (1993) demonstrated that increasing feed intake in nonpregnant sheep lowers circulating progesterone by increasing the metabolic clearance rate. Similarly, in a separate study on lactating and non-lactating cows, both liver blood flow and steroid clearance were affected by feed intake (Sangsritavong et al. 2002). Increased dietary intake during pregnancy also appears to increase steroid clearance. Pregnant adult sheep offered the same high quantities of the complete diet as the adolescent animals in the present study exhibit reduced progesterone concentrations but, when compared with controls, there was no significant difference in placental and foetal weights (Wallace et al. 2005a). Recent studies in overnourished adolescent sheep have shown that a 50\% reduction in circulating progesterone in late gestation (day 130) can be reversed by switching animals from a high to a low intake diet at day 90 (moderate: $13.9 \pm 1.0$; high: $6.9 \pm 0.83$; high to low: $17.3 \pm 1.44$ ). This change in peripheral progesterone levels occurred independent of changes in placental size in that equivalent placental growth restriction was evident in high and high-low groups $(293 \pm 23.9$ vs $375 \pm 48.0$ g respectively; D A
Redmer and J M Wallace, unpublished observations). In contrast to the overfeeding model, underfeeding adolescent ewes $(0.75 \%$ maintenance diet from embryo transfer) has no effect on term placental size but increases circulating progesterone concentrations by $70 \%$ (J S Luther and J M Wallace, unpublished observations). In these experiments, switching the animals to a moderate intake diet at day 90 decreased circulating progesterone to levels comparable with the moderate intake control group by day 130 (moderate: $18.8 \pm 3.4$; underfed: $32.1 \pm 5.0$; underfed to moderate: $21.2 \pm 2.9)$. In the present study, mid-gestation day 81 ewes on a high intake diet exhibit a decrease in circulating progesterone but no difference in placental size. Since the live weight gain averaged to day 81 is significantly greater in the overnourished group, these animals have a higher metabolic activity. Indeed, a sustained elevation of maternal tri-iodothyronine and thyroxine concentrations in high intake adolescent ewes from mid-gestation provides further evidence of an increase in metabolic rate (Wallace et al. 1997a). Therefore, it is likely that the mid-gestation decrease in circulating progesterone is due to an increase in maternal metabolic clearance.

At late gestation, ewes on high nutrient intakes, both with and without IUGR foetuses, had a higher mean live weight gain than moderately fed control ewes. Therefore, an increase in maternal metabolic clearance may at least partly account for lower levels of progesterone in late gestation high intake ewes. However, progesterone concentrations in the most perturbed high intake ewes with IUGR foetuses were $56 \%$ lower than in high intake ewes with non-IUGR foetuses. Since the mean live weight gain of the two high intake groups was equivalent, maternal metabolic clearance clearly does not entirely account for the decrease in progesterone observed in IUGR pregnancies. Low maternal progesterone levels in this subgroup appear to be associated with the smaller placental size that characterises this group. In addition, the decreased abundance of Cyp11A1 transcripts suggests that the smaller placentas also exhibit reduced biosynthetic activity and are unable to compensate for the reduced size. In support of a possible contributory effect on biosynthesis, we have shown that late gestation peripheral progesterone concentrations positively associate with the expression of both Cyp11A1 and Hsd3b, whereas there was no evidence for a similar relationship at mid-gestation.

In conclusion, mid- and late gestation overnourished adolescent sheep exhibit reduced systemic levels of oPL and progesterone. At mid-gestation, there are no similar changes in the expression of placental oPL, StAR and the steroidogenic enzymes important for progesterone synthesis. Since placental size is equivalent at this time point, mid-gestation circulating maternal levels of oPL and progesterone most likely reflect altered placental differentiation and/or, with respect to progesterone, 
increased maternal metabolic clearance. At late gestation, the lowest progesterone concentrations were found in the high intake animals with IUGR. These ewes also had smaller placentas than non-IUGR high intake animals and a decreased expression of placental Cyp11A1 indicative of altered progesterone biosynthesis. Since the high intake subgroups had equivocal live weight gains, reduced placental size and impaired progesterone biosynthesis appear to be key contributory factors to the late gestation reduction in circulating progesterone in IUGR pregnancies.

\section{Acknowledgements}

The authors thank G Horgan (Biomathematics \& Statistics Scotland, Edinburgh, Scotland) for statistical assistance and Morven Cruickshank for the progesterone analyses reported in experiment 1. This work was supported by the Scottish Executive Environment and Rural Affairs Department (SEERAD) as part of the core funding to the Rowett Research Institute. The authors declare that there is no conflict of interest that would prejudice the impartiality of this scientific work.

\section{References}

Al-Gubory KH, Solari A \& Mirman B 1999 Effects of luteectomy on the maintenance of pregnancy, circulating progesterone concentrations and lambing performance in sheep. Reproduction Fertility and Development 11 317-322.

Bell AW, Wilkening RB \& Meschia G 1987 Some aspects of placental function in chronically heat-stressed ewes. Journal of Developmental Physiology 9 17-29.

Burrin DG, Ferrell CL, Eisemann JH, Britton RA \& Nienaber JA 1989 Effect of level of nutrition on splanchnic blood flow and oxygen consumption in sheep. British Journal of Nutrition 62 23-34.

Green JA, Xie S, Quan X, Bao B, Gan X, Mathialagan N, Beckers JF \& Roberts RM 2000 Pregnancy-associated bovine and ovine glycoproteins exhibit spatially and temporally distinct expression patterns during pregnancy. Biology of Reproduction 62 1624-1631.

Heinonen S, Taipale P \& Saarikoski S 2001 Weights of placentae from small-for-gestational age infants revisited. Placenta 22 399-404.

Hoffman LH \& Wooding FB 1993 Giant and binucleate trophoblast cells of mammals. Journal of Experimental Zoology 266 559-577.

Kappes SM, Warren WC, Pratt SL, Liang R \& Anthony RV 1992 Quantification and cellular localization of ovine placental lactogen messenger ribonucleic acid expression during mid- and late gestation. Endocrinology 131 2829-2838.

Lacroix MC, Bolifraud P, Durieux D, Pauloin A, Vidaud M \& Kann G 2002 Placental growth hormone and lactogen production by perifused ovine placental explants: regulation by growth hormonereleasing hormone and glucose. Biology of Reproduction $\mathbf{6 6}$ 555-561.

Lea RG, Hannah LT, Redmer DA, Aitken RP, Milne JS, Fowler PA, Murray JF \& Wallace JM 2005 Developmental indices of nutritionally- induced placental growth restriction in the adolescent sheep. Pediatric Research 57 599-604.

Linzell JL \& Heap RB 1968 A comparison of progesterone metabolism in the pregnant sheep and goat: sources of production and an estimation of uptake by some target organs. Journal of Endocrinology $41433-438$.
Mason JI, France JT, Magness RR, Murry BA \& Rosenfeld CR 1989 Ovine placental steroid 17 alpha-hydroxylase/C-17,20-lyase, aromatase and sulphatase in dexamethasone-induced and natural parturition. Journal of Endocrinology 122 351-359.

Parr RA 1992 Nutrition-progesterone interactions during early pregnancy in sheep. Reproduction Fertility and Development $\mathbf{4}$ 297-300.

Parr RA, Davis IF, Miles MA \& Squires TJ 1993 Liver blood flow and metabolic clearance rate of progesterone in sheep. Research in Veterinary Science 55 311-316.

Redmer D, Aitken RP, Milne JS, Reynolds LP \& Wallace JM 2005 Influence of maternal nutrition on messenger RNA expression of placental angiogenic factors and their receptors at midgestation in adolescent sheep. Biology of Reproduction 72 1004-1009.

Regnault TR, Orbus RJ, Battaglia FC, Wilkening RB \& Anthony RV 1999 Altered arterial concentrations of placental hormones during maximal placental growth in a model of placental insufficiency. Journal of Endocrinology 162 433-442.

Riley SC, Boshnier DP, Luu-The V, Labrie F \& Challis JRG 1991 Distribution and localisation of 3B-hydroxysteroid dehydrogenase (3B-HSD) in the sheep placentome throughout gestation using immunocytochemical techniques. Journal of Reproduction and Fertility (Abstract) Series 743.

Robinson JS, Kingston EJ, Jones CT \& Thorburn GD 1979 Studies on experimental growth retardation in sheep. The effect of removal of endometrial caruncles on foetal size and metabolism. Journal of Developmental Physiology 1 379-398.

Ronayne E \& Hynes N 1990 Measurement of plasma progesterone concentrations by extraction and non-extraction radioimmunoassays. Irish Journal of Agricultural Research 29 109-115.

Rusell AJF, Doney JM \& Gunn RG 1969 Subjective assessment of body fat in live sheep. Journal of Agricultural Science 72 451-454.

Rusovici R, Hui YY \& Lavoie HA 2005 Epidermal growth factormediated inhibition of follicle-stimulating hormone-stimulated StAR gene expression in porcine granulosa cells is associated with reduced histone $\mathrm{H} 3$ acetylation. Biology of Reproduction 72 $862-871$.

Sangsritavong S, Combs DK, Sartori R, Armentano LE \& Wilbank MC 2002 High feed intake increases liver blood flow and metabolism of progesterone and estradiol-17beta in dairy cattle. Journal of Dairy Science 85 2831-2842.

Schoknecht PA, McGuire MA, Cohick WS, Currie WB \& Bell AW 1996 Effect of chronic infusion of placental lactogen on ovine fetal growth in late gestation. Domestic Animal Endocrinology 13 519-528.

Scholl TO \& Hediger ML 1993 A review of the epidemiology of nutrition and adolescent pregnancy: maternal growth during pregnancy and its effect on the fetus. Journal of the American College of Nutrition 12 101-107.

Scholl TO, Hediger ML \& Schall JI 1997 Maternal growth and foetal growth: pregnancy course and outcome in the Camden Study. Annals of New York Academy of Sciences 817 292-301.

Strauss JF III, Martinez F \& Kiriakidou M 1996 Placental steroid hormone synthesis: unique features and unanswered questions. Biology of Reproduction 54 303-311.

Su YX, Carey LC \& Rose JC 2004 Ontogeny of StAR and ACTH-R genes in ovine placenta. Placenta 25 658-663.

Thureen PJ, Trembler KA, Meschia G, Makowski EL \& Wilkening RB 1992 Placental glucose transport in heat-induced foetal growth retardation. American Journal of Physiology 263 R578-R585.

Tuckey RC 2005 Progesterone synthesis by the human placenta. Placenta 26 273-281.

Ullman MB \& Reimers TJ 1989 Progesterone production by bovine trophoblastic cells. Journal of Reproduction and Fertility 37 173-179.

Vanselow J, Furbass R, Rehbock F, Klautschek G \& Schwerin M 2004 Cattle and sheep use different promoters to direct the expression of the aromatase cytochrome P450 encoding gene, Cyp19, during pregnancy. Domestic Animal Endocrinology 27 99-114. 
Wallace JM, Aitken RP \& Cheyne MA 1996 Nutrient partitioning and foetal growth in rapidly growing adolescent ewes. Journal of Reproduction and Fertility 107 183-190.

Wallace JM, Da Silva P, Aitken RP \& Cruickshank MA 1997a Maternal endocrine status in relation to pregnancy outcome in rapidly growing adolescent sheep. Journal of Endocrinology 155 359-368.

Wallace JM, Aitken RP, Cheyne MA \& Humblot P 1997b Pregnancyspecific protein $\mathrm{B}$ and progesterone concentrations in relation to nutritional regimen, placental mass and pregnancy outcome in growing adolescent ewes carrying singleton fetuses. Journal of Reproduction and Fertility 109 53-58.

Wallace JM, Bourke DA, Aitken RP \& Cruickshank MA 1999 Switching maternal dietary intake at the end of the first trimester has profound effects on placental development and foetal growth in adolescent ewes carrying singleton fetuses. Biology of Reproduction 61 $101-110$

Wallace JM, Bourke DA, Aitken RP, Palmer RM, Da Silva P \& Cruickshank MA 2000 Relationship between nutritionally-mediated placental growth restriction and foetal growth, body composition and endocrine status during late gestation in adolescent sheep. Placenta 21 100-108.

Wallace J, Bourke D, Da Silva P \& Aitken R 2001 Nutrient partitioning during adolescent pregnancy. Reproduction 122 347-357.

Wallace JM, Bourke DA, Aitken RP, Leitch N \& Hay WW Jr 2002 Blood flows and nutrient uptakes in growth-restricted pregnancies induced by overnourishing adolescent sheep. American Journal of Physiology - Regulatory, Integrative and Comparative Physiology 282 R1027-R1036.

Wallace JM, Bourke DA, Da Silva P \& Aitken RP 2003 Influence of progesterone supplementation during the first third of pregnancy on foetal and placental growth in overnourished adolescent ewes. Reproduction 126 481-487.

Wallace JM, Milne JS \& Aitken RP 2004 Maternal growth hormone treatment from day 35 to 80 of gestation alters nutrient partitioning in favor of uteroplacental growth in the overnourished adolescent sheep. Biology of Reproduction 70 1277-1285.

Wallace JM, Milne JS \& Aitken RP 2005a The effect of overnourishing singleton-bearing adult ewes on nutrient partitioning to the gravid uterus. British Journal of Nutrition 94 533-539.
Wallace JM, Regnault TR, Limesand SW, Hay WW \& Anthony RV $2005 b$ Investigating the causes of low birth weight in contrasting ovine paradigms. Journal of Physiology 565 19-26.

Wallace JM, Matsuzaki M, Milne J \& Aitken R 2006a Late but not early gestational maternal growth hormone treatment increases fetal adiposity in overnourished adolescent sheep. Biology of Reproduction 75 231-239.

Wallace JM, Luther JS, Milne JS, Redmer DA, Reynolds LP \& Hay WW $2006 b$ Nutritional modulation of adolescent pregnancy outcome - a review. Placenta 27 S61-S68.

Wango EO, Heap RB \& Wooding FB 1991 Progesterone and 5 betapregnanediol production by isolated foetal placental binucleate cells from sheep and goats. Journal of Endocrinology 129 283-289.

Westergaard JG, Teisner B, Hau J \& Grudzinskas JG 1984 Placental protein measurements in complicated pregnancies. I. Intrauterine growth retardation. British Journal of Obstetrics and Gynaecology 91 1216-1223.

Wooding FBP 1981 Localization of ovine placental lactogen in sheep placentomes by electron microscope immunocytochemistry. Journal of Reproduction and Fertility 62 15-19.

Wooding FB, Flint AP, Heap RB, Morgan G, Buttle HL \& Young IR 1986 Control of binucleate cell migration in the placenta of sheep and goats. Journal of Reproduction and Fertility 76 499-512.

Wooding FB, Morgan G, Monaghan S, Hamon M \& Heap RB 1996 Functional specialization in the ruminant placenta: evidence for two populations of foetal binucleate cells of different selective synthetic capacity. Placenta 17 75-86.

Yanaihara T, Hirato K, Seo F, Mitsukawa G, Kojima S, Maruyama S, Nakayama T \& Suzuki K 1984 Prenatal diagnosis of IUGR by assessing the multiple hormone concentration in maternal peripheral blood. Nippon Sanka Fujinka Gakkai Zasshi 36 182-188.

Received 24 October 2006

First decision 16 November 2006

Revised manuscript received 7 January 2007

Accepted 15 January 2007 